\title{
ROS and Brain Diseases: The Good, the Bad, and the Ugly
}

\author{
Aurel Popa-Wagner, ${ }^{1}$ Smaranda Mitran, ${ }^{2}$ Senthilkumar Sivanesan, ${ }^{3}$ \\ Edwin Chang, ${ }^{4}$ and Ana-Maria Buga, ${ }^{1,2}$ \\ ${ }^{1}$ Department of Psychiatry, Rostock University Medical School, Gehlsheimer Straße 20, 18147 Rostock, Germany \\ ${ }^{2}$ Center of Clinical and Experimental Medicine, University of Medicine and Pharmacy, 200349 Craiova, Romania \\ ${ }^{3}$ Department of Biomedical Sciences, College of Veterinary Medicine, Ames, IA 50011, USA \\ ${ }^{4}$ Stanford University School of Medicine, MIPS, Canary Center at Stanford for Cancer Early Detection, CA 94304, USA
}

Correspondence should be addressed to Aurel Popa-Wagner; aurel.popa-wagner@med.uni-rostock.de

Received 12 August 2013; Revised 4 November 2013; Accepted 5 November 2013

Academic Editor: Cinzia Signorini

\begin{abstract}
Copyright (C) 2013 Aurel Popa-Wagner et al. This is an open access article distributed under the Creative Commons Attribution License, which permits unrestricted use, distribution, and reproduction in any medium, provided the original work is properly cited.

The brain is a major metabolizer of oxygen and yet has relatively feeble protective antioxidant mechanisms. This paper reviews the Janus-faced properties of reactive oxygen species. It will describe the positive aspects of moderately induced ROS but it will also outline recent research findings concerning the impact of oxidative and nitrooxidative stress on neuronal structure and function in neuropsychiatric diseases, including major depression. A common denominator of all neuropsychiatric diseases including schizophrenia and ADHD is an increased inflammatory response of the brain caused either by an exposure to proinflammatory agents during development or an accumulation of degenerated neurons, oxidized proteins, glycated products, or lipid peroxidation in the adult brain. Therefore, modulation of the prooxidant-antioxidant balance provides a therapeutic option which can be used to improve neuroprotection in response to oxidative stress. We also discuss the neuroprotective role of the nuclear factor erythroid 2-related factor (Nrf2) in the aged brain in response to oxidative stressors and nanoparticle-mediated delivery of ROS-scavenging drugs. The antioxidant therapy is a novel therapeutic strategy. However, the available drugs have pleiotropic actions and are not fully characterized in the clinic. Additional clinical trials are needed to assess the risks and benefits of antioxidant therapies for neuropsychiatric disorders.
\end{abstract}

\section{Introduction}

The earth began its life without free oxygen in its atmosphere [1]. Oxygen accumulation is a consequence of the establishment and propagation of photosynthesizing archea and bacteria on this planet [2]. With the arrival of the world's first de facto pollutant (i.e., oxygen), approximately 3 billion years ago there evolved organisms that reductively metabolized oxygen to produce ATP in mitochondria [3] (i.e., aerobic respiration). Mitochondrial energy metabolism yields several reactive oxygen species (ROS) including oxygen ions $\left(\mathrm{O}_{2}{ }^{-}\right.$, the primary ROS), free radicals, and peroxides (inorganic and organic). The presence of ROS produced profound consequences for life on earth, both beneficial and deleterious. For example, a wealth of evidence suggests that high levels of ROS are intimately linked to the appearance of neuronal death in various neurological disorders. These include chronic diseases (Parkinson's disease or Alzheimer's disease) [4], acute injury of the brain (brain trauma and cerebral ischemia) $[5,6]$, or psychiatric disorders (autism, attention deficit hyperactivity disorder, depression, and schizophrenia) [7].

An increase in oxidative and nitrooxidative stress and a decrease in the antioxidant capacity of the brain are key factors involved in the etiology of neuropsychiatric diseases (Figure 1). In the following we will detail both the beneficial and deleterious impacts of these Janus-faced processes.

\section{ROS Are Required for Physiological Processes}

Even though ROS are involved in a number of diseases, they are also very pertinent mediators of several normal physiological processes. All of the good ROS are products 


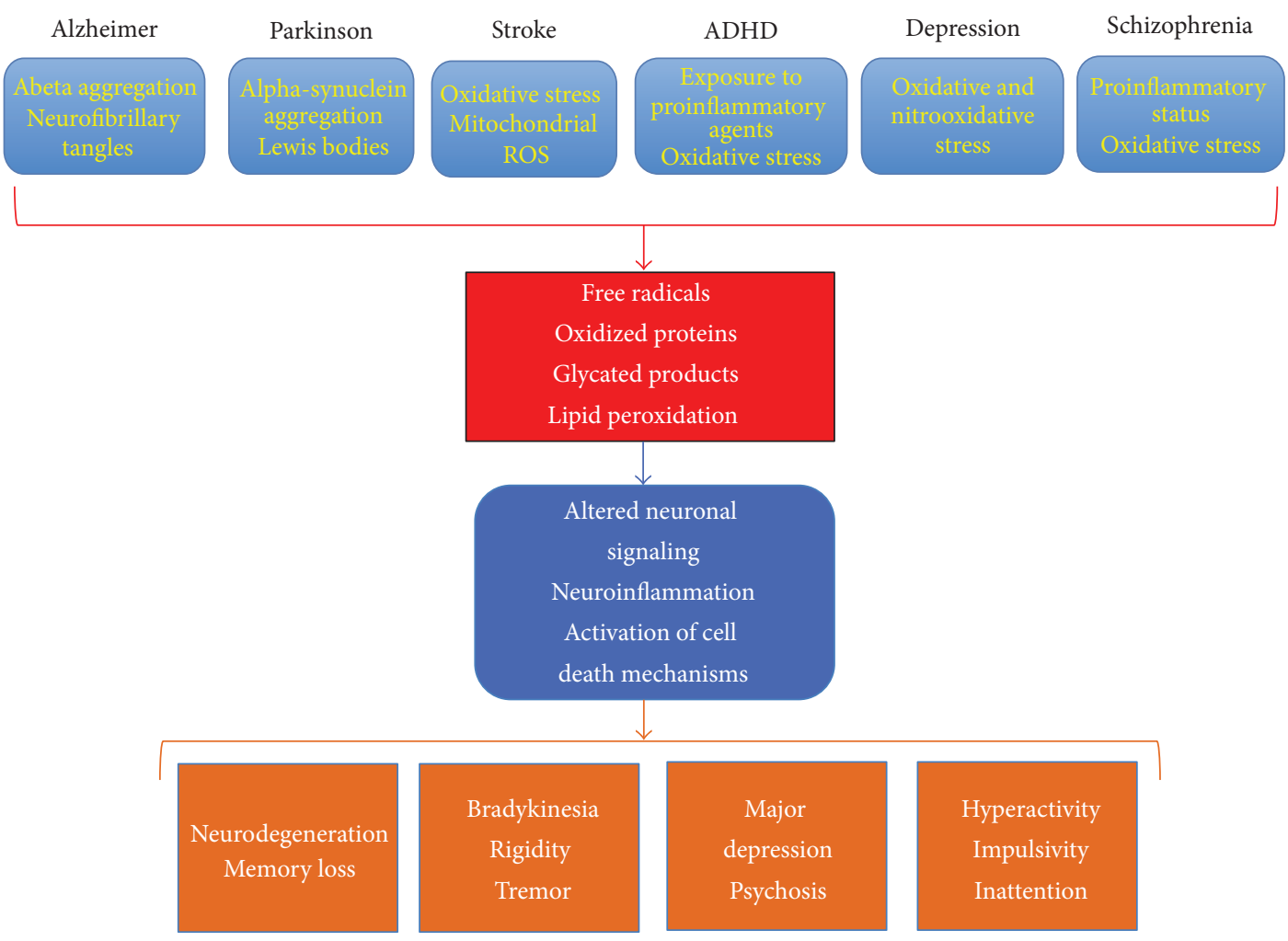

FIGURE 1: Schematic representation of oxidative stress-related mechanisms underlying disease development in Alzheimer's disease (AD), Parkinson disease (PD), stroke, attention deficit and hyperactivity disorders (ADHD), schizophrenia, and depression.

of turnover in the mitochondrial respiratory chain. The highly reactive nature of singlet oxygen can even be exploited to make reactive peroxides that can serve as antimicrobial agents [8]. Most of the physiological effects are in fact mediated by reactive oxygen species (ROS) derivatives of superoxide. Similarly, the superoxide anion $\left(\mathrm{O}_{2}{ }^{-\bullet}\right)$, through its derivative, the hydroxyl radical $(\bullet \mathrm{OH})$, plays an essential role in cell physiology by stimulating the activation of guanylate cyclase and formation of the "second messenger" cGMP in cells and activation of the transcription factor nuclear factor $\mathrm{kB}(\mathrm{NF}-\mathrm{kB})$ by hydrogen peroxide in mammalian cells [9]. Under normal physiological conditions, the NO radical $(\mathrm{NO} \bullet$ ) regulates the vascular tone by smooth muscle relaxation.

In the inflammatory response, macrophages and neutrophils are attracted by activated T lymphocytes and IL-2 and produce high levels of $\mathrm{O}_{2}{ }^{-}$, which along with other ROS destroy the engulfed bacteria (oxidative burst) [10]. In brain tissue, ROS are generated by microglia and astrocytes and modulate synaptic and nonsynaptic communication between neurons and glia. ROS also interfere with increased neuronal activity [11] by modifying the myelin basic protein and can induce synaptic long-term potentiation, a form of activitydependent synaptic plasticity and memory consolidation. Furthermore, results from animal models suggest that the role of $\mathrm{O}_{2}{ }^{-}$in modulating synaptic plasticity, memory formation, and learning is altered by age [12].

\section{Deleterious Effects Associated with ROS}

Activated oxygen species, especially those that share electronic orbital features with singlet oxygen, are highly reactive, and therefore the evolutionary adaptation by organisms to make oxygen wholly beneficial has never been complete. Consequently, there are many deleterious effects associated with excessive, activated ROS. ROS are thereby capable of producing membrane damage, changes in the inner proteins affecting their structure and function, lipids denaturation, and structural damage to DNA. In the brain, those effects appear when ROS are in excessive concentrations and thus the ability of antioxidant mechanisms of neurons to counterbalance the damaging reactions is diminished [13].

The brain is especially susceptible to the assaults perpetrated by ROS. This is because the brain as an organ is a major metabolizer of oxygen ( $20 \%$ of the body consumption) and yet has relatively feeble protective antioxidant mechanisms. Thus it is especially vulnerable to oxidative stress. The brain contains a large amount of polyunsaturated peroxidizable fatty acids along with high levels of iron that act as a prooxidant and sometimes induce autophagic cell death in hemorrhagic stroke. Synaptic transmission involving dopamine and glutamate oxidation may also occur in the brain [13-15]. In addition, lipid peroxidation leads to the production of toxic compounds such aldehydes or dienals (e.g., 4-hydroxynonenal) which may cause in turn neuronal apoptosis [16]. 
At the DNA level, oxidative modifications may cause rapid depletion of intracellular energy by activating DNA repair enzymes. Energy scarcity after stroke will cause in turn endonuclease-mediated DNA fragmentation, the key mechanism that leads to DNA-damage [17].

\section{Brain Mitochondrion and Oxidative Stress}

The mitochondria is the cellular powerhouse that generates ATP and therefore is a key participant in all physiological and pathological events. Following ischemia-associated excitotoxicity and other neurodegenerative insults, mitochondria will take up calcium which leads to an increased production of reactive oxygen species (ROS). As a result, neuronal cells face excessive amounts of ROS [18]. The mechanisms linking mitochondrial calcium uptake and ROS production are incompletely understood but may involve an increase in the permeability of the mitochondrial membranes to small molecules and thereby initiate cell death through release of apoptosis-inducing factors via the opening of an as yet unidentified megapore protein [18-21].

Once opened, the pore can cause the collapse of the proton gradient. This promotes collapse of respiratory control as well as release of $\mathrm{Ca}^{2+}$ stored in the mitochondrial matrix. Furthermore, since the mitochondrial matrix is negatively charged, $\mathrm{K}^{+}$can enter through the pore and cause osmotic swelling [22]. A bioenergetics failure ensues due to the inhibition of oxidative phosphorylation and ATP synthesis. The few ATP molecules generated by glycolysis or by residual functional mitochondria are hydrolyzed by ATP synthase that work in reverse under such extreme conditions [22]. If the pore remains open for a long period major consequences for energy metabolism and even cellular death may occur.

An increasing number of studies report the prevalence of oxidative stress and mitochondrial abnormalities in numerous neuropsychiatric disorders [23-30]. A spectrum of oxidative stress markers involved in schizophrenia and anxiety related disorders were thoroughly categorized based on several biochemical assays $[31,32]$ as well as genetic assessment studies [32]. Recent genetic studies pinpoint at mutations in several genes encoding proteins required for synaptic plasticity suggesting a plausible link between neuropsychiatric diseases and neurodevelopmental abnormalities [33,34]. Notably, mutations in PTEN-induced kinase 1 (PINK1) gene function have been attributed to oxidative stress and mitochondrial fragmentation [35]. However, alterations in GMP-PKG signaling leading to increased brain phosphodiesterase-2 (PDE2) levels $[26,36,37]$ and NOX2dependent mechanisms [38] are believed to drive oxidative stress-related events in the pathogenesis of psychiatric disorders.

Defects in the electron transport chain (ETC) system and especially the mitochondrial complex dysfunctions have been reported to be involved in autism $[39,40]$ and schizophrenia [40]. Additionally, defects in pyruvate dehydrogenase activity and copy number variations in mtDNA were also seen in autistic subjects [40]. In a more recent work, involving a transgenic mouse model that expresses the gene, "putative dominant-negative disrupted in schizophrenia 1" (DNDISC1), a plausible mechanistic link between prefrontal oxidative stress and neuropsychiatric problems was explored [41]. Likewise, more recent genetic studies point to alterations in a set of genes associated with epigenetic mechanisms and oxidative stress pathology thereby suggesting histone modifications and DNA methylation in schizophrenia related psychopathology [42].

\section{Oxidative Stress Mediated Inflammation and Neuropsychiatric Diseases}

Recent findings suggest that neuroinflammation is an important player in the pathophysiology of neuropsychiatric diseases such as stroke, depression, Alzheimer's diseases, or schizophrenia $[43,44]$.

5.1. Cerebral Ischemia (CI). After the onset of cerebral ischemia, oxidative stress plays a major role in neuroinflammatory reactions $[45,46]$. In postischemic brains, oxidative stress triggers activation of microglia and astrocytes [47] leading to striking elevations in the levels of inflammatory mediators such as cytokines, chemokines, and matrix metalloproteases [48] and causing the loss of endothelial cell integrity in the brain as manifested by upregulation of cell adhesion molecules and neutrophil infiltration [49]. This probably provokes subsequently secondary inflammation and glial immune response resulting in permanent brain cell damage [48].

Redox-mediated increase in free radicals in the postischemic brains notably leads to augmented expression of several proinflammatory genes whose expression is mediated through the transcription factor nuclear factor-kappa- $\mathrm{B}$ or NF- $\kappa$ B [48]. Importantly, NF- $\kappa$ B mediated proinflammatory reactions and innate immune responses are prominent features in cerebral ischemic conditions [50-52]. Although activation of innate immunity by Toll-like receptors seems to promote regenerative mechanisms [53], neuronal loss critically involves ROS induced TLR-mediated inflammatory responses during cerebral ischemia [54-57].

5.2. Parkinson's Disease. In Parkinson's disease (PD), a considerable body of evidence suggests that both dopaminergic and nondopaminergic cells undergo degeneration [58-60]. The innate immune response seen in the CNS of PD subjects involves a spectrum of oxidative stress and inflammatory responses that cause neurodegeneration. However, the key loss of dopaminergic neurons involves oxidative stress and neuroinflammatory mechanisms through increased levels of inducible nitric oxide synthase (iNOS) followed by activated microglia, T-cell infiltration, and astrogliosis leading to accumulation of $\mathrm{O}_{2}{ }^{-}$and $\mathrm{NO}$ free radicals [59]. Dopaminergic neuronal loss via oxidative stress-mediated inflammation also involves cyclooxygenase-2 (COX2) overexpression [59]. Additionally, higher levels of myeloperoxidase, generated by reactive astrocytes, could even elevate the levels of reactive $(\bullet \mathrm{OH})$ and $\mathrm{NO}_{2}{ }^{-}$radicals that could in turn lead to neuronal 
loss in Parkinson's disease [59]. Similarly, the upregulation of NADPH-oxidase, which is known to be associated with inflammation and ROS generation, in PD has been tied to microglial activation, local ROS elevation, and subsequent dopaminergic neuronal loss [61].

The involvement of microglial activation most likely attracts lymphocytes to the site of injury. Subsequent pathophysiological sequelae involve damage to the integrity of the blood brain barrier (BBB), and then increased shedding of several inflammatory cytokines into the cerebral spinal fluid (CSF) of PD patients $[62,63]$. As reactive microgliosis seems to be a major event in $\mathrm{PD}$ pathogenesis, altered cytokines and ROS levels in microglia [64] as well as augmented microglial NADPH-derived ROS accumulation [65] all contribute to the neurotoxicity seen in PD.

The research findings from Reynolds and colleagues implicate the role of adaptive immunity functions during microglial inflammation in Parkinson's disease [66]. On the other hand, the effector T-cell (E) responses are believed to be the mediators of microglial activation and subsequent neurodegeneration. Taken together, both innate and adaptive immunity play consistent, prominent roles in causing neuronal death in $\mathrm{PD}$.

5.3. Alzheimer's Disease (AD). Major events associated with oxidative stress could exacerbate inflammation-related pathologies in Alzheimer's disease (AD) [67-69]. Recent reports suggest that oxidative stress-mediated binding of advanced glycation endproduct (AGE) to its receptor (RAGE) can adversely increase the microglial inflammation and cytokine release. Such events contribute to neuronal loss in $\mathrm{AD}$ [70]. In $\mathrm{AD}$ patients, both reactive astrocytes and microglial activation are involved in amyloid beta proteinmediated oxidative stress and inflammation [71-73] as well as compromised immune responses [71] within the cerebral parenchyma. Recent genomic studies [74] in AD patients confirmed previous observations that showed upregulation of several pathways associated with the innate immune system following microglia activation and inflammation in aging. The researchers concluded that such findings would ultimately account for neurodegeneration and memory loss in $\mathrm{AD}$.

The important role conferred to Toll-like receptors (TLR2 and TLR4) in $\mathrm{AD}$ as peripheral biomarkers [75] of $\mathrm{AD}$ pathophysiology [75-77] is well studied. Notably, the part played by TLR receptors in AD progression addresses the importance of innate immune responses [78]. However, the striking elevation of TLR4 expression in neurons by the toxic action of Abeta 1-42 or by increased elevation of the lipid peroxidation product, 4-hydroxynonenal (HNE), obviously suggests that oxidative stress does drive neuronal loss in $\mathrm{AD}$ [77].

5.4. Multiple Sclerosis. The demyelination and axonal damage triggered by oxidative stress and inflammatory reactions are widely reported in multiple sclerosis (MS) [79]. The subsequent appearance of peroxynitrate molecules is believed to inflict severe damage to brain cells and especially neurons
[80]. Recently, both ROS and RNS (reactive nitrogen species) compounds are considered to be the early causative factors for the inflammatory reactions associated with MS. This subsequently leads to considerable loss of oligodendrocytes and axons [81]. Moreover, the early mitochondrial damage caused by oxidative stress seems to be critical for subsequent inflammatory processes and neuronal loss in multiple sclerosis [82].

5.5. Neurodevelopmental Disorders. Epidemiological studies on prenatal exposure to infection during the developmental period suggests that the immune system plays an important role in a number of disorders such as schizophrenia, depression, or cognitive impairment [83]. The innate immune system triggers a cascade of events that results in an increased synthesis of cytokines, interferons, and other immunological mediators thereby altering the balance of proand anti-inflammatory cytokines. Since cytokine receptors are expressed as early as the fetal period, it is thought that inflammatory cytokines may represent a key mechanism involved in neurodevelopmental disorders [84, 85]. Indeed, recent studies have shown that prenatal exposure to proinflammatory agents like Il-6, Il-8, and TNF alpha can increase the risk for diseases like autism or schizophrenia by inducing both neuromorphological and neurochemical changes in the immature brain [86-88].

The vulnerability to develop psychiatric diseases later in life (fetal programming) involves not only the immune response of the brain, but also the changes in glial cell function $[89,90]$. Thus, assessment of microglia in postmortem autism cases revealed a strong microglial cortical activation suggesting that activated microglia may play a central role in the pathogenesis of autism [91].

5.6. Depressive Disorders. Major depressive disorders are often associated with an increased inflammatory response of the brain. A study employing the serotonin transporter (SERT) mutant rats has shown that deletion of the SERT gene is associated with an increased level of proinflammatory cytokines and an increased number of activated microglia suggesting that the serotonin transporter dysfunction plays an important role in the pathogenesis of depressive disorders via an increased glial response to inflammatory agents [92, 93]. More specific, Macchi and colleagues [93] showed that the SERT mutant rats displayed an activated microglial phenotype under basal conditions. The mechanisms for microglial activation and its consequences are still not completely understood. However, several studies investigating the role of proinflammatory cytokines like tumor necrosis factor (TNF) alpha or interleukins (IL1 beta, IL6, and IL8) have involved microglial activation in schizophrenia pathogenesis $[94,95]$.

The progression of bipolar disorders is multifactorial and include the interaction between the neurotransmitters, neuropeptides, oxidative and nitrosative stress and cytokines, and neurotrophins including BDNF [96, 97]. Most importantly, emerging evidence in animal models and also in 
humans suggests that anti-inflammatory therapy may delay the progression of the diseases [98].

\section{Biomarkers of Oxidative Stress in Neuropsychiatric Diseases}

The levels of several growth factors and metabolites are altered in cerebral tissue, cerebrospinal fluid (CSF), and serum of patients exposed to oxidative stress and can be used to assess risk factors or as potential biomarkers. Similarly, longitudinal in vivo ${ }^{1} \mathrm{H}$-MRS that was used to evaluate the postinjury evolution of 20 individual neurochemicals after traumatic brain injury (TBI) revealed a dramatic depletion of glutathione (GSH) and ascorbate (Asc), two endogenous antioxidants with the highest concentration in the central nervous system [99]. The following sections give an account of current biomarkers of oxidative stress in neuropsychiatric diseases.

6.1. Developmental Disorders. Although many of the cognitive and behavioral features of autism spectrum disorders (ASD) are associated with dysfunctions of the central nervous system, ASD also appears to be associated with systemic metabolic abnormalities such as oxidative stress and mitochondrial dysfunction [100-102]. Glutathione deficiency also contributes to abnormalities seen in autistic behavior $[40,103]$ as well as schizophrenia and bipolar disorders [104]. Likewise, examination of urinary samples from schizophrenia subjects revealed considerable alterations in 8-oxo-7,8-dihydro-20-deoxyguanosine and 8oxo-7,8-dihydroguanosine levels indicating oxidative stress induced nucleic acids damage [105]. Similarly, in plasma F2dihomo-isoprostanes, a specific component of myelin in the brain of primates, plasma represents an early marker of Rett syndrome, a developmental disorder that almost exclusively affects females but has been found in male patients, too [106].

A recent meta-analysis of oxidative stress in schizophrenia suggests that red blood cells (RBC) SOD levels and to a lesser extent RBC catalase and plasma nitrites, were significantly decreased in acutely relapsed inpatients, firstepisode psychosis, and stable medicated outpatients [107].

Several markers of lipid peroxidation including the ubiquitous lipid peroxidation product, malondialdehyde (MDA), have been found to be significantly increased in ADHD patients. The study comprised 20 adult-ADHD patients and 21 healthy volunteers, to whom malondialdehyde levels were measured in plasma. The study evaluated indirectly the level of ROS and found that the mean plasma MDA levels of patients having adult-ADHD were significantly higher than those of the control group. The results suggest a relation between oxidative metabolism and adult ADHD [108].

6.2. Depressive Disorders. Studies conducted on postmortem tissue from depressed patients have shown reduced levels of hippocampal, an anatomical structure involved in anxiety and depressive behaviors, as well as cortical BDNF [109]. In addition, a polymorphism in the BDNF gene has been associated with depression [110-113].
In the periphery, a meta-analysis provided strong evidence that BDNF levels in serum of depressed subjects are lower as compared to those of the healthy controls. Further, the antidepressant treatment restored BDNF to normal levels [114].

After adipose tissue, the organ with the highest lipid content is the brain and elevated serum levels of lipid peroxidation products have been often reported in bipolar disorders. Because the axonal membranes and myelin sheaths of the brain are rich in lipids, it has been proposed that lipid peroxidation products may be promising peripheral biomarkers of underlying white matter abnormalities in bipolar disorders (BP). A recent study combined diffusion tensor imaging and biochemical analysis of serum to examine relationships between measures of white matter integrity as measured by fractional anisotropy, radial diffusivity, and peripheral measures of lipid peroxidation, the lipid hydroperoxides, LPH and 4-hydroxy-2-nonenal, 4-HNE. The study suggests that serum LPH may be useful in the development of a clinically relevant assay for peripheral biomarkers of $\mathrm{BD}$ [115].

Similarly, lipofuscin granule accumulation has been described in biopsies from patients suffering from major depressive disorder (MDD) indicating the impact of oxidative stress on neurovascular abnormalities in these patients [116].

6.3. Alzheimer Disease. Mitochondrial dysfunction can also be detected in peripheral tissues. Although erythrocytes are considered as passive "reporter cells" for the oxidative status of the whole organism, decreased glutathione peroxidase activity (GPx) in RBC may be considered as a new peripheral marker for AD [117]. Several other studies showed a decreased cytochrome c activity and increased levels of ROS in human platelets from AD patients [118-120]. Similarly, lymphocytes of AD patients are characterised by increased basal ROS levels [121].

Other classical markers of oxidative stress in plasma of early stage $\mathrm{AD}$ patients include thiobarbituric acid reactive substances (TBARS) as an index of lipid peroxidation, protein carbonyl content as an index of protein oxidation, the enzymatic activities of GPx, catalase (CAT), and superoxide dismutase (SOD) as well as the plasma levels of total glutathione (reduced GSH plus oxidized glutathione (GSSG) [122].

6.4. Parkinson's Disease. Similarly, 4-hydroxynonenal (4HNE), an alpha, beta-unsaturated hydroxyalkenal produced by peroxidation of polyunsaturated fatty acids, is widely recognized as a specific marker of oxidative stress both centrally and in the CSF and serum of PD patients [123-127].

Likewise, several markers of lipid peroxidation including the ubiquitous lipid peroxidation product, malondialdehyde (MDA), have been found to be significantly increased in PD brains [128-131]. There is also strong evidence for lipid peroxidation products like hydroxyeicosatetraenoic acid in plasma, leukocytes, and erythrocytes from PD patients [132134]. Finally, higher nitric oxide and peroxynitrite serum 
levels have been recently reported in Parkinson's disease versus controls [135].

\section{Targets of Therapy in Neuropsychiatric Disorders}

Oxidative stress and neuroinflammation are key factors contributing to aging of the brain. Many studies highlighted the importance of antioxidative defenses in the aging process $[22,136,137]$, but it is still unclear whether these responses are beneficial or detrimental. A diminished endogenous antioxidative capacity of the brain can promote aged-related diseases such as cerebral ischemia or neurodegenerative disorders. In order to protect the brain from both agedassociated pathological diseases and the aging process itself, it becomes imperative to understand the molecular and cellular mechanisms of antioxidative and/or inflammatory response.

7.1. Activators of the Nrf2/ARE Pathway. The nuclear factor erythroid 2 related factor (Nrf2) is a dimer of the p45 protein and a member of the small Maf family proteins involved in the modulation of both antioxidant and anti-inflammatory signaling [138].

As cells are permanently exposed to a variety of oxidative stressors they must be able to trigger antioxidative signaling pathways in order to maintain redox homeostasis. To this end Nrf2 is activated, via phosphorylation, while under oxidative stress (such as in hypoxia/ischemia reperfusion or in neurodegenerative diseases) it is shuttled to the nucleus where it builds up a dimer with the small Maf. The activated complex in turn promotes the transcription of genes involved in neuroprotection. An in vitro study on primary cortical cultures has recently shown that prolonged expression of the transcription factor NF-E2-related factor 2 (Nrf2) induced by hypoxia and oxidative stress acts neuroprotectively against oxygen glucose deprivation. By inserting the Nrf2 gene in an inducible gene construct, a controlled, neuroprotective effect can be achieved by overexpressing Nrf2 not only during hypoxia but also after reperfusion [139].

The key trigger to this neuroprotective cascade is the binding of Nrf2 to the antioxidant response elements (AREs) [140-142]. Therefore, exogenous Nrf2/ARE activators may represent powerful drugs to activate the antioxidant and defensive acting genes. The Nrf2/ARE pathway can be pharmacologically activated both by natural products such as sulforaphane [143, 144], polyphenols, epigallocatechin 3gallate (EGCG), and curcumin [145] and synthetic drugs including triterpenoids and N-(4-(2-pyridyl)(1,3-thiazol-2yl))-2-(2,4,6-trimethylphenoxy) acetamide, known as CPN-9 [146].

Interestingly, recent studies have also shown that Nrf2/ Hmox activation may enhance cell proliferation and survival in the subventricular zone (SVZ) of aged brains by reverting microglial phenotype into the proneurogenic phenotype [147, 148]. We also have observed that during conditions of cerebral ischemia, the aged brain upregulates the Hmoxl gene only partially and later (day 14 after-ischemia) as compared to young animals which activate this gene strongly and early (day 3 after-infarct) after stroke [149].

7.2. Biochemicals: Omega-3 Polyunsaturated Fatty Acids and Vitamins. Of these, omega-3 polyunsaturated fatty acid (PUFA) is one of the few compounds that are able to modulate the expression of genes involved in cell signaling, division, apoptosis, and oxidative stress [150]. Mounting evidence indicates that fatty acid deficiencies or imbalances may also contribute to a range of adult psychiatric and neurologic disorders including ADHD, DCD (developmental coordination disorder), and autism.

A recent study investigated the antioxidant effect of alpha linolenic acid in adults and children with ADHD, DCD, and autism. Omega-3 polyunsaturated fatty acids were given as supplements to patients diet, and the changes in hyperactivity, attention, and other disruptive behaviors were analyzed. The patients who received flax oil (an oil rich in 18 carbon omega-3 fatty alpha-linolenic acid) did show a significant improvement in the symptoms of ADHD reflected by a reduction in total hyperactivity scores [151]. However, the diet with mixed omega- 3 and omega- 6 supplementation had only a modest effect on attention and hyperactivity symptoms in 117 children with DCD. The treatment did not show a significant effect on motor skills but did show a significant improvement in reading, spelling, and behavior versus placebo during the 3 months of treatment [152].

Vitamins have also been used in clinical trials. A study was performed on patients over 70 years old, who were diagnosed with dementia and other cognitive dysfunctions [153]. An improvement in their cognitive performance was observed, after vitamin $\mathrm{C}$ and $\mathrm{E}$ were given as food supplements. Of note, a positive response was seen in vascular dementia but not in Alzheimer's disease [153]. In other studies, long-term high dosing of vitamin E supplementation increased the risk of hemorrhagic stroke and other causes of mortality, raising questions about the benefit or the harm of this treatment [154]. The presence of vitamin D seems to regulate autophagy that is used by the cell to degrade cytosolic macromolecules and organelles in the lysosome. Being an adaptive response, the autophagy can be useful or deleterious depending on the energetic status of the cell $[155,156]$.

\section{Peroxisome Proliferator-Activated Receptor-Gamma Agonists}

In human and animal models, the cognitive decline in vascular dementia is dependent on the hippocampal function. Recently, peroxisome proliferator-activated receptor gamma (PPAR-gamma) agonists were shown to diminish oxidative stress, inflammation, and apoptosis in the central nervous system $[157,158]$. Peroxisome-proliferator activator receptorgamma is a nuclear receptor with a key role in energy homeostasis and inflammation that has been implicated in the oxidative stress response.

Telmisartan is a special angiotensin II receptor blocker (ARB) and a partial agonist of the (PPAR-gamma). A recent study asked if telmisartan protects against cognitive decline 
in a rat model of vascular dementia. Indeed, it was found that telmisartan acts neuroprotectively against cognitive decline after cerebral ischemia by promoting anti-inflammatory and antioxidant effects $[159,160]$. In particular, it has been hypothesized that ARB might act neuroprotectively by upregulating the levels of BDNF, a known antioxidant, in the hippocampus. Indeed, after 28 days of treatment with telmisartan, BDNF expression in the hippocampus was significantly higher as compared to controls and the animals showed an improved cognitive performance. It was inferred that telmisartan may protect the cells via upregulation of $\mathrm{BDNF}$ and its receptor TrkB, in the hippocampus possibly via angiotensin II-induced anti-oxidative stress [161]. Recently, another PPAR-gamma agonist, 15d-PGJ2, has been shown to exert neuroprotection by inhibiting neuronal autophagy in stroke model [162].

Thiazolidinediones (TZDs) are still another potent synthetic agonists of PPAR-gamma that have been successfully used to diminish inflammation after cerebral ischemia [163]. Similarly, pioglitazone and rosiglitazone are two TZDs with proven efficacy in reducing inflammation and upregulating antioxidant enzymes after spinal cord injury [164]. Recently, the neuroprotective efficacy of a TZD-unrelated PPARgamma agonist L-796,449 has been tested in an animal model of stroke. The study showed that L-796,449 decreased the infarct size and improved neurologic outcomes [165].

8.1. Gases: Hyperbaric Oxygen and $\mathrm{H}_{2} \mathrm{~S}$. The first study that used hyperbaric oxygen therapy to treat autistic children showed a significant level of improvement of autistic symptoms in $75 \%$ of patients [166]. The results have been confirmed in a second study that evaluated social development, fine motor and eye-hand coordination, language development, gross motor development, and self-help skills, before and after the treatment of children with autism. It should be noted that the beneficial effect of hyperbaric oxygen for brain diseases has been previously shown by D. A. Rossignol and L. W. Rossignol in 2006 who showed that hyperbaric oxygen therapy improved oxygen levels in ischemic area by increasing the oxygen concentration in plasma as a compensatory mechanism in hypoxia [167].

Hydrogen sulfide $\left(\mathrm{H}_{2} \mathrm{~S}\right)$ is another gas recently used in several neuroprotective studies. $\mathrm{H}_{2} \mathrm{~S}$ is a mild inhibitor of oxidative phosphorylation and can protect neurons after a stroke [168]. The study was performed on 17-month-old male Sprague-Dawley rats, and focal cerebral ischemia was induced by reversible occlusion of the right middle cerebral artery. Exposure of poststroke rats to a mixture of air and hydrogen sulfide for 2 days resulted in deep and sustained hypothermia $\left(31.8 \pm 0.7^{\circ} \mathrm{C}\right)$. An improvement in the poststroke recovery of complex sensorimotor skills along with a $50 \%$ reduction in infarct size was noted. There were no obvious physiological side effects. Hypothermia resulted in a reduction in the number of phagocytic cells as well as decreased transcriptional activity of several genes related to inflammation and apoptosis including caspase 12, NF-kappa $\mathrm{B}$, and grp78 in the peri-infarcted region [168].
Two further studies showed that indeed hydrogen-rich saline can benefit the brain in a global cerebral ischemia/ reperfusion model (four-vessel occlusion model) and in a rat model with permanent focal cerebral ischemia (permanent middle cerebral artery occlusion), respectively $[169,170]$. The results demonstrated that intraperitoneal injection of hydrogen-rich saline offers strong neuroprotective effects by reducing oxidative stress and inflammation. Thus, the level of endogenous antioxidant enzymes (superoxide dismutaseSOD and catalase-CAT) was increased, whereas the concentration of oxidative products (8-iso-PGF $2 \alpha$ and malondialdehyde) and inflammatory cytokines (TNF- $\alpha$ and IL-6) was decreased $[169,170]$.

8.2. Metals: Lithium. Healthy volunteers treated with lithium for a period of 2-4 weeks showed decreased superoxide dismutase levels and superoxide dismutase/catalase ratio as well as diminished hydrogen peroxide concentrations. Therefore, lithium has a potential role for neuroprotection in bipolar disorders and even in neurodegenerative diseases. Lithium seems to be the gold standard due to its ability to prevent/or reverse DNA damage, lipid peroxidation, and free radical formation [171]. In addition, lithium induces BDNF in neuronal cultures [172].

8.3. ROS Scavengers. A mechanism that implicates the oxidative stress in the appearance of depressive symptoms is the metabolism of the nitric oxide (NO). NO is generated by nitric oxide synthase (NOS) that catalyzes the metabolism of L-arginine to L-citrulline and nitric oxide $(\bullet \mathrm{NO})$ in the presence of molecular oxygen and NADPH. NO is a gas that acts as second messenger in a number of organs, including the brain, and is also a free radical involved in the etiology and progression of many diseases.

Neuronal NOS (nNOS) is a Ca2+-calmodulin-dependent isoform of NOS that is constitutively expressed in neuronal cells. A persistent expression of nNOS may result in an increased production of reactive nitrogen species (RNS), such as $\bullet \mathrm{NO}$ and peroxynitrite $\left(\mathrm{ONOO}^{-}\right)$and thus may result in neuronal death due to increased nitrative/nitrosative stress. NOS can also generate superoxide when levels of the natural substrates L-arginine and tetrahydrobiopterin decrease [173].

The "NO hypothesis" was tested in a small clinical study done on 78 patients diagnosed with recurrent depressive disorder and healthy controls. High levels of plasma NO were tested along with the efficiency of visual-spatial and auditoryverbal working memory and short-term declarative memory. The concentration of plasma NO was found to be directly proportional with the severity of depressive symptoms [174].

In a recent study, Yoshitomi and colleagues [175] have reported the synthesis of $\mathrm{pH}$-responsive nitroxide radicalcontaining nanoparticles which act as highly efficient scavengers of ROS, thus bringing new hopes for antioxidant therapies.

Recently it is has been suggested that not only antioxidants, but also the prooxidant system plays an important role in neuropsychiatric disorders. Xanthine oxidase (XO) is an enzyme of special interest in this context, since it acts as 
TABLE 1: Drugs with anti-inflammatory and antioxidant effects currently under investigation for the treatment of several neuropsychiatric diseases.

\begin{tabular}{|c|c|c|c|}
\hline Drug & Brain disease & Mechanism & Reference \\
\hline$\omega$-3 PUFA & ADHD & Nonspecific antioxidant effect & {$[151,152]$} \\
\hline Vitamin C & Vascular dementia & Free radical scavenger & {$[153]$} \\
\hline Hyperbaric $\mathrm{O}_{2}$ & Autism & Anti-inflammatory and reduces oxidative stress & [157] \\
\hline $\mathrm{H}_{2} \mathrm{~S}$ & $\begin{array}{l}\text { Focal cerebral } \\
\text { ischemia/reperfusion }\end{array}$ & $\begin{array}{l}\text { Inhibits oxidative phosphorylation, } \\
\text { inflammation, and apoptosis }\end{array}$ & [159] \\
\hline $\mathrm{H}_{2}$-rich saline & $\begin{array}{l}\text { Focal or global cerebral } \\
\text { ischemia/reperfusion }\end{array}$ & Reduces oxidative stress and inflammation & {$[160,161]$} \\
\hline Lithium & Healthy volunteers & $\begin{array}{l}\text { Prevents/or reverses DNA damage, lipid } \\
\text { peroxidation, and free radical formation }\end{array}$ & {$[164]$} \\
\hline Pifithrin- $\mu$ & $\begin{array}{l}\text { Perinatal hypoxic-ischemic } \\
\text { brain damage }\end{array}$ & $\begin{array}{l}\text { Inhibition of the apoptotic pathways and } \\
\text { reduction of the oxidative stress }\end{array}$ & {$[166]$} \\
\hline Telmisartan & Vascular dementia & Anti-inflammatory and antioxidant effects & {$[174-176]$} \\
\hline Nanodrugs & & ROS scavengers & {$[177]$} \\
\hline Triterpenoids & Parkinson & Antioxidants via Nrf2/ARE pathway & {$[146]$} \\
\hline $\begin{array}{l}\text { PPARgamma } \\
\text { agonists }\end{array}$ & Neurodegenerative diseases & Anti-inflammatory & {$[162-164]$} \\
\hline
\end{tabular}

a prooxidant, but its main product uric acid is a powerful antioxidant. By examining the activity of $\mathrm{XO}$ in the occipital cortex and thalamus of patients with psychosis, the authors found a decreased activity of XO suggesting a downregulation of cellular defence mechanisms in schizophrenia [176].

The available drugs currently in use either for research or therapeutic purposes for several brain diseases are shown in Table 1 .

\section{Conclusions}

Here we reviewed many aspects of therapeutic strategies aimed to improve the neuroprotection and the function of the brain. Many preclinical models showed an increased neuroprotection to stressors like hypoxia. Although many promising drugs, in particular antioxidants, have been developed and shown to be beneficial to experimental animal models, the results of recent clinical trials investigating these promising drugs have been largely negative. As alluded to previously, the oxidative stress is a key contributor to neurodegeneration. Therefore, the antioxidant therapy is a novel therapeutic strategy and neuroscientists are increasingly interested in the participation of ROS towards the pathology involved in neurodegenerative disorders. It is, however, difficult to determine targets for treatment and to distinguish between what may be harmful or beneficial for the brain, without precise knowledge of the pathways involved in the progression of neuronal diseases [178].

Modulation of prooxidant-antioxidant balance plays an important role in mitochondrial dysfunction and provides an additional therapeutic option which can be used to improve neuroprotection and cognitive functions in response to oxidative stress. Anti-ROS drugs could probe pathological pathways associated with neurodegeneration psychiatric disorders. However, there are only few well-established drugs of such a kind and the risks and benefits are still not fully clarified. Most likely, multiple distinct pathways should be targeted for an efficient therapeutic purpose. Therefore it is not surprisingly that many drugs exert their beneficial effects on neurotransmission indirectly by modulating inflammation, oxidative stress, or apoptosis [179]. Meta-analyses have suggested that antidepressants (fluvoxamine, reboxetine, or imipramine) and antipsychotics (clozapine and risperidone) reduce the levels of the proinflammatory cytokines IL-6 and NO and suppress the macrophage production [177] and upregulate signaling pathway associated with neurotrophic factors like BDNF [180, 181]. Likewise, fluoxetine may exert its neuroprotective effects via downregulating the expression of inhibiting key players involved in inflammation including NFkappaB [182], IL-1 $\beta$, TNF- $\alpha$, and COX-2 [183]. However, the available drugs have pleiotropic actions and are not fully characterized in the clinic.

\section{Authors' Contribution}

Aurel Popa-Wagner, Smaranda Mitran, Senthil Kumar, Edwin Chang, and Ana-Maria Buga have equally contributed to this work.

\section{Acknowledgments}

This study was supported by UEFISCDI, PN-II-PCCA-2011 Grant no. 80, to Aurel Popa-Wagner and UEFISCDI FLARE2 to Ana-Maria Buga.

\section{References}

[1] M. Dole, “The natural history of oxygen," The Journal of General Physiology, vol. 49, no. 1, pp. 5-27, 1965.

[2] N. A. Campbell and J. B. Reece, Biology, Pearson-Benjamin Cummings, 7th edition, 2005. 
[3] P. R. Rich, “The molecular machinery of Keilin's respiratory chain," Biochemical Society Transactions, vol. 31, no. 6, pp. 10951105, 2003.

[4] M. Guglielmotto, E. Tamagno, and O. Danni, "Oxidative stress and hypoxia contribute to Alzheimer's disease pathogenesis: two sides of the same coin," TheScientificWorldJournal, vol. 9, no. 1, pp. 781-791, 2009.

[5] S.-D. Chen, D.-I. Yang, T.-K. Lin, F.-Z. Shaw, C.-W. Liou, and Y.-C. Chuang, "Roles of oxidative stress, apoptosis, PGC-1 and mitochondrial biogenesis in cerebral ischemia," International Journal of Molecular Sciences, vol. 12, no. 10, pp. 7199-7215, 2011.

[6] M. Valko, D. Leibfritz, J. Moncol, M. T. D. Cronin, M. Mazur, and J. Telser, "Free radicals and antioxidants in normal physiological functions and human disease," International Journal of Biochemistry and Cell Biology, vol. 39, no. 1, pp. 44-84, 2007.

[7] T. M. Michel, D. Pülschen, and J. Thome, "The role of oxidative stress in depressive disorders," Current Pharmaceutical Design, vol. 18, no. 36, pp. 5890-5899, 2012.

[8] X. Wang and X. Zhao, "Contribution of oxidative damage to antimicrobial lethality," Antimicrobial Agents and Chemotherapy, vol. 53, no. 4, pp. 1395-1402, 2009.

[9] W. Dröge, "Free radicals in the physiological control of cell function," Physiological Reviews, vol. 82, no. 1, pp. 47-95, 2002.

[10] S.-P. Lu, M.-H. Lin Feng, H.-L. Huang, Y.-C. Huang, W.-I. Tsou, and M.-Z. Lai, "Reactive oxygen species promote raft formation in T lymphocytes," Free Radical Biology \& Medicine, vol. 42, no. 7, pp. 936-944, 2007.

[11] C. M. Atkins and J. D. Sweatt, "Reactive oxygen species mediate activity-dependent neuron-glia signaling in output fibers of the hippocampus," The Journal of Neuroscience, vol. 19, no. 17, pp. 7241-7248, 1999.

[12] D. Hu, F. Serrano, T. D. Oury, and E. Klann, "Aging-dependent alterations in synaptic plasticity and memory in mice that overexpress extracellular superoxide dismutase," The Journal of Neuroscience, vol. 26, no. 15, pp. 3933-3941, 2006.

[13] S. L. Mehta, S. Kumari, N. Mendelev, and P. A. Li, "Selenium preserves mitochondrial function, stimulates mitochondrial biogenesis, and reduces infarct volume after focal cerebral ischemia," BMC Neuroscience, vol. 13, article 79, 2012.

[14] N. Badjatia, D. Seres, A. Carpenter et al., "Free fatty acids and delayed cerebral ischemia after subarachnoid hemorrhage," Stroke, vol. 43, no. 3, pp. 691-696, 2012.

[15] G. Chen, C. H. Jing, P. P. Liu, D. Ruan, and L. Wang, "Induction of autophagic cell death in the rat brain caused by iron," The American Journal of the Medical Sciences, vol. 345, no. 5, pp. 369-374, 2013.

[16] E. McCracken, V. Valeriani, C. Simpson, T. Jover, J. McCulloch, and D. Dewar, "The lipid peroxidation by-product 4hydroxynonenal is toxic to axons and oligodendrocytes," Journal of Cerebral Blood Flow and Metabolism, vol. 20, no. 11, pp. 1529-1536, 2000.

[17] J. Cui, E. H. Holmes, T. G. Greene, and P. K. Liu, “Oxidative DNA damage precedes DNA fragmentation after experimental stroke in rat brain," FASEB Journal, vol. 14, no. 7, pp. 955-967, 2000.

[18] A. Panov, S. Dikalov, N. Shalbuyeva, R. Hemendinger, J. T. Greenamyre, and J. Rosenfeld, "Species- and tissue-specific relationships between mitochondrial permeability transition and generation of ROS in brain and liver mitochondria of rats and mice," American Journal of Physiology-Cell Physiology, vol. 292, no. 2, pp. C708-C718, 2007.
[19] M. J. Hansson, R. Månsson, S. Morota et al., "Calcium-induced generation of reactive oxygen species in brain mitochondria is mediated by permeability transition," Free Radical Biology \& Medicine, vol. 45, no. 3, pp. 284-294, 2008.

[20] W. O. Opii, V. N. Nukala, R. Sultana et al., "Proteomic identification of oxidized mitochondrial proteins following experimental traumatic brain injury," Journal of Neurotrauma, vol. 24, no. 5, pp. 772-789, 2007.

[21] J. J. Lemasters, T. P. Theruvath, Z. Zhong, and A.-L. Nieminen, "Mitochondrial calcium and the permeability transition in cell death," Biochimica et Biophysica Acta, vol. 1787, no. 11, pp. 13951401, 2009.

[22] A. Rasola, M. Sciacovelli, B. Pantic, and P. Bernardi, "Signal transduction to the permeability transition pore," FEBS Letters, vol. 584, no. 10, pp. 1989-1996, 2010.

[23] B. Halliwell, "Oxidative stress and neurodegeneration: where are we now?" Journal of Neurochemistry, vol. 97, no. 6, pp. 1634$1658,2006$.

[24] E. H. Tobe, "Mitochondrial dysfunction, oxidative stress, and major depressive disorder," Neuropsychiatric Disease and Treatment, vol. 9, pp. 567-573, 2013.

[25] S. Tsaluchidu, M. Cocchi, L. Tonello, and B. K. Puri, "Fatty acids and oxidative stress in psychiatric disorders," BMC Psychiatry, vol. 8, supplement 1, article S5, 2008.

[26] A. Masood, A. Nadeem, S. J. Mustafa, and J. M. O'Donnell, "Reversal of oxidative stress-induced anxiety by inhibition of phosphodiesterase-2 in mice," Journal of Pharmacology and Experimental Therapeutics, vol. 326, no. 2, pp. 369-379, 2008.

[27] M. J. Arranz and J. de Leon, "Pharmacogenetics and pharmacogenomics of schizophrenia: a review of last decade of research," Molecular Psychiatry, vol. 12, no. 8, pp. 707-747, 2007.

[28] J. Bouayed, H. Rammal, C. Younos, and R. Soulimani, "Positive correlation between peripheral blood granulocyte oxidative status and level of anxiety in mice," European Journal of Pharmacology, vol. 564, no. 1-3, pp. 146-149, 2007.

[29] J. Bouayed, H. Rammal, and R. Soulimani, "Oxidative stress and anxiety Relationship and cellular pathways," Oxidative Medicine and Cellular Longevity, vol. 2, no. 2, pp. 63-72, 2009.

[30] D. Marazziti, S. Baroni, M. Picchetti et al., "Psychiatric disorders and mitochondrial dysfunctions," European Review for Medical and Pharmacological Sciences, vol. 16, no. 2, pp. 270-275, 2012.

[31] I. Hovatta, J. Juhila, and J. Donner, "Oxidative stress in anxiety and comorbid disorders," Neuroscience Research, vol. 68, no. 4, pp. 261-275, 2010.

[32] F. Ng, M. Berk, O. Dean, and A. I. Bush, "Oxidative stress in psychiatric disorders: evidence base and therapeutic implications," International Journal of Neuropsychopharmacology, vol. 11, no. 6, pp. 851-876, 2008.

[33] B. D. Auerbach, E. K. Osterweil, and M. F. Bear, "Mutations causing syndromic autism define an axis of synaptic pathophysiology," Nature, vol. 480, no. 7375, pp. 63-68, 2011.

[34] E. Ben-David and S. Shifman, "Networks of neuronal genes affected by common and rare variants in autism spectrum disorders," PLoS Genetics, vol. 8, no. 3, Article ID e1002556, 2012.

[35] R. K. Dagda, S. J. Cherra III, S. M. Kulich, A. Tandon, D. Park, and C. T. Chu, "Loss of PINK1 function promotes mitophagy through effects on oxidative stress and mitochondrial fission," The Journal of Biological Chemistry, vol. 284, no. 20, pp. 13843$13855,2009$.

[36] F. G. Boess, M. Hendrix, F.-J. van der Staay et al., "Inhibition of phosphodiesterase 2 increases neuronal cGMP, synaptic 
plasticity and memory performance," Neuropharmacology, vol. 47, no. 7, pp. 1081-1092, 2004.

[37] C. Werner, G. Raivich, M. Cowen et al., "Importance of NO/cGMP signalling via cGMP-dependent protein kinase II for controlling emotionality and neurobehavioural effects of alcohol," European Journal of Neuroscience, vol. 20, no. 12, pp. 3498-3506, 2004.

[38] X. Wang, A. Pinto-Duarte, T. J. Sejnowski, and M. M. Behrens, "How Nox2-containing NADPH oxidase affects cortical circuits in the NMDA receptor antagonist model of schizophrenia," Antioxidants \& Redox Signaling, vol. 18, no. 12, pp. 1444-1462, 2013.

[39] D. A. Rossignol and R. E. Frye, "A review of research trends in physiological abnormalities in autism spectrum disorders: immune dysregulation, inflammation, oxidative stress, mitochondrial dysfunction and environmental toxicant exposures," Molecular Psychiatry, vol. 17, no. 4, pp. 389-401, 2012.

[40] F. Gu, V. Chauhan, K. Kaur et al., "Alterations in mitochondrial DNA copy number and the activities of electron transport chain complexes and pyruvate dehydrogenase in the frontal cortex from subjects with autism," Translational Psychiatry, vol. 3, article e299, 2013.

[41] A. W. Johnson, H. Jaaro-Peled, N. Shahani et al., "Cognitive and motivational deficits together with prefrontal oxidative stress in a mouse model for neuropsychiatric illness," Proceedings of the National Academy of Sciences of the United States of America, vol. 110, no. 30, pp. 12462-12467, 2013.

[42] S. Kano, C. Colantuoni, F. Han et al., "Genome-wide profiling of multiple histone methylations in olfactory cells: further implications for cellular susceptibility to oxidative stress in schizophrenia," Molecular Psychiatry, vol. 18, no. 7, pp. 740-742, 2012.

[43] M. Kubera, B. Grygier, D. Wrona et al., "Stimulatory effect of antidepressant drug pretreatment on progression of B16F10 melanoma in high-active male and female C57BL/6J mice," Journal of Neuroimmunology, vol. 240-241, pp. 34-44, 2011.

[44] M. Maes, Z. Fišar, M. Medina, G. Scapagnini, G. Nowak, and M. Berk, "New drug targets in depression: inflammatory, cell-mediated immune, oxidative and nitrosative stress, mitochondrial, antioxidant, and neuroprogressive pathways. And new drug candidates-Nrf2 activators and GSK-3 inhibitors," Inflammopharmacology, vol. 20, no. 3, pp. 127-150, 2012.

[45] X. Wang and E. H. Lo, "Triggers and mediators of hemorrhagic transformation in cerebral ischemia," Molecular Neurobiology, vol. 28, no. 3, pp. 229-244, 2003.

[46] M. Godínez-Rubí, A. E. Rojas-Mayorquín, and D. OrtuñoSahagún, "Nitric oxide donors as neuroprotective agents after an ischemic stroke-related inflammatory reaction," Oxidative Medicine and Cellular Longevity, vol. 2013, Article ID 297357, 16 pages, 2013.

[47] S. Love, "Oxidative stress in brain ischemia," Brain Pathology, vol. 9, no. 1, pp. 119-131, 1999.

[48] S. E. Lakhan, A. Kirchgessner, and M. Hofer, "Inflammatory mechanisms in ischemic stroke: therapeutic approaches," Journal of Translational Medicine, vol. 7, article 97, 2009.

[49] G. J. del Zoppo and J. M. Hallenbeck, "Advances in the vascular pathophysiology of ischemic stroke," Thrombosis Research, vol. 98, no. 3, pp. V73-V81, 2000.

[50] O. A. Harari and J. K. Liao, "NF- $\kappa$ B and innate immunity in ischemic stroke," Annals of the New York Academy of Sciences, vol. 1207, pp. 32-40, 2010.
[51] T. C. Nichols, "NF- $\kappa$ B and reperfusion injury," Drug News \& Perspectives, vol. 17, no. 2, pp. 99-104, 2004.

[52] Z. Wei, S. Chigurupati, T. V. Arumugam, D.-G. Jo, H. Li, and S. L. Chan, "Notch activation enhances the microglia-mediated inflammatory response associated with focal cerebral ischemia," Stroke, vol. 42, no. 9, pp. 2589-2594, 2011.

[53] J. M. Pradillo, D. Fernández-López, I. García-Yébenes et al., "Toll-like receptor 4 is involved in neuroprotection afforded by ischemic preconditioning," Journal of Neurochemistry, vol. 109, no. 1, pp. 287-294, 2009.

[54] J. R. Caso, J. M. Pradillo, O. Hurtado, P. Lorenzo, M. A. Moro, and I. Lizasoain, "Toll-like receptor 4 is involved in brain damage and inflammation after experimental stroke," Circulation, vol. 115, no. 12, pp. 1599-1608, 2007.

[55] J. R. Caso, J. M. Pradillo, O. Hurtado, J. C. Leza, M. A. Moro, and I. Lizasoain, "Toll-like receptor 4 is involved in subacute stress-induced neuroinflammation and in the worsening of experimental stroke," Stroke, vol. 39, no. 4, pp. 1314-1320, 2008.

[56] R. Gill, A. Tsung, and T. Billiar, "Linking oxidative stress to inflammation: toll-like receptors," Free Radical Biology \& Medicine, vol. 48, no. 9, pp. 1121-1132, 2010.

[57] Y. Suzuki, K. Hattori, J. Hamanaka et al., "Pharmacological inhibition of TLR4-NOX4 signal protects against neuronal death in transient focal ischemia," Surface Science Reports, vol. 2, article 896, 2012.

[58] P. Jenner and C. W. Olanow, "The pathogenesis of cell death in Parkinson's disease," Neurology, vol. 66, no. 10, supplement 4, pp. S24-S36, 2006.

[59] E. C. Hirsch and S. Hunot, "Neuroinflammation in Parkinson's disease: a target for neuroprotection?" The Lancet Neurology, vol. 8, no. 4, pp. 382-397, 2009.

[60] D. A. Gallagher and A. H. V. Schapira, "Etiopathogenesis and treatment of Parkinson's disease," Current Topics in Medicinal Chemistry, vol. 9, no. 10, pp. 860-868, 2009.

[61] D.-C. Wu, P. Teismann, K. Tieu et al., "NADPH oxidase mediates oxidative stress in the 1-methyl-4-phenyl-1,2,3,6tetrahydropyridine model of Parkinson's disease," Proceedings of the National Academy of Sciences of the United States of America, vol. 100, no. 10, pp. 6145-6150, 2003.

[62] D. Blum-Degena, T. Müller, W. Kuhn, M. Gerlach, H. Przuntek, and P. Riederer, "Interleukin-1 $\beta$ and interleukin- 6 are elevated in the cerebrospinal fluid of Alzheimer's and de novo Parkinson's disease patients," Neuroscience Letters, vol. 202, no. 1-2, pp. 17-20, 1995.

[63] F. González-Scarano and G. Baltuch, "Microglia as mediators of inflammatory and degenerative diseases," Annual Review of Neuroscience, vol. 22, pp. 219-240, 1999.

[64] M. M. Pabon, A. D. Bachstetter, C. E. Hudson, C. Gemma, and P. C. Bickford, "CX3CL1 reduces neurotoxicity and microglial activation in a rat model of Parkinson's disease," Journal of Neuroinflammation, vol. 8, article 9, 2011.

[65] B. Joglar, J. Rodriguez-Pallares, A. I. Rodriguez-Perez, P. Rey, M. J. Guerra, and J. L. Labandeira-Garcia, "The inflammatory response in the MPTP model of Parkinson's disease is mediated by brain angiotensin: relevance to progression of the disease," Journal of Neurochemistry, vol. 109, no. 2, pp. 656-669, 2009.

[66] A. D. Reynolds, D. K. Stone, R. L. Mosley, and H. E. Gendelman, "Nitrated $\alpha$-synuclein-induced alterations in microglial immunity are regulated by CD4+ T cell subsets," Journal of Immunology, vol. 182, no. 7, pp. 4137-4149, 2009. 
[67] W. R. Markesbery and J. M. Carney, "Oxidative alterations in Alzheimer's disease,” Brain Pathology, vol. 9, no. 1, pp. 133-146, 1999.

[68] M. Verri, O. Pastoris, M. Dossena et al., "Mitochondrial alterations, oxidative stress and neuroinflammation in Alzheimer's disease," International Journal of Immunopathology and Pharmacology, vol. 25, no. 2, pp. 345-353, 2012.

[69] K. Leuner, W. E. Müller, and A. S. Reichert, "From mitochondrial dysfunction to amyloid beta formation: novel insights into the pathogenesis of Alzheimer's disease," Molecular Neurobiology, vol. 46, no. 1, pp. 186-193, 2012.

[70] P. Younessi and A. Yoonessi, "Advanced glycation end-products and their receptor-mediated roles: inflammation and oxidative stress," Iranian Journal of Medical Sciences, vol. 36, no. 3, pp. 154166, 2011.

[71] R. N. Kalaria, M. Harshbarger-Kelly, D. L. Cohen, and D. R. D. Premkumar, "Molecular aspects of inflammatory and immune responses in Alzheimer's disease," Neurobiology of Aging, vol. 17, no. 5, pp. 687-693, 1996.

[72] K. D. Bornemann, K.-H. Wiederhold, C. Pauli et al., "A $\beta$ induced inflammatory processes in microglia cells of APP23 transgenic mice," American Journal of Pathology, vol. 158, no. 1, pp. 63-73, 2001.

[73] M. Kitazawa, T. R. Yamasaki, and F. M. LaFerla, "Microglia as a potential bridge between the amyloid $\beta$-peptide and tau," Annals of the New York Academy of Sciences, vol. 1035, pp. 85103, 2004.

[74] D. H. Cribbs, N. C. Berchtold, V. Perreau et al., "Extensive innate immune gene activation accompanies brain aging, increasing vulnerability to cognitive decline and neurodegeneration: a microarray study," Journal of Neuroinflammation, vol. 9, article 179, 2012.

[75] W. Zhang, L.-Z. Wang, J.-T. Yu, Z.-F. Chi, and L. Tan, "Increased expressions of TLR2 and TLR4 on peripheral blood mononuclear cells from patients with Alzheimer's disease," Journal of the Neurological Sciences, vol. 315, no. 1-2, pp. 67-71, 2012.

[76] J.-J. Jin, H.-D. Kim, J. A. Maxwell, L. Li, and K.-I. Fukuchi, "Toll-like receptor 4-dependent upregulation of cytokines in a transgenic mouse model of Alzheimer's disease," Journal of Neuroinflammation, vol. 5, article 23, 2008.

[77] S.-C. Tang, J. D. Lathia, P. K. Selvaraj et al., "Toll-like receptor-4 mediates neuronal apoptosis induced by amyloid $\beta$-peptide and the membrane lipid peroxidation product 4-hydroxynonenal," Experimental Neurology, vol. 213, no. 1, pp. 114-121, 2008.

[78] C. R. Balistreri, G. Colonna-Romano, D. Lio, G. Candore, and C. Caruso, "TLR4 polymorphisms and ageing: Implications for the pathophysiology of age-related diseases," Journal of Clinical Immunology, vol. 29, no. 4, pp. 406-415, 2009.

[79] D. A. Drechsel, A. G. Estévez, L. Barbeito, and J. S. Beckman, "Nitric oxide-mediated oxidative damage and the progressive demise of motor neurons in ALS," Neurotoxicity Research, vol. 22, no. 4, pp. 251-264, 2012.

[80] R. E. Gonsette, "Neurodegeneration in multiple sclerosis: the role of oxidative stress and excitotoxicity," Journal of the Neurological Sciences, vol. 274, no. 1-2, pp. 48-53, 2008.

[81] T. Zeis, A. Probst, A. J. Steck, C. Stadelmann, W. Brück, and N. Schaeren-Wiemers, "Molecular changes in white matter adjacent to an active demyelinating lesion in early multiple sclerosis: molecular changes in MS periplaque white matter," Brain Pathology, vol. 19, no. 3, pp. 459-466, 2009.

[82] M. T. Fischer, R. Sharma, J. L. Lim et al., "NADPH oxidase expression in active multiple sclerosis lesions in relation to oxidative tissue damage and mitochondrial injury," Brain, vol. 135, no. 3, pp. 886-899, 2012.

[83] U. Ratanayake, T. Quinn, D. W. Walker, and H. Dickinson, "Cytokines and the neurodevelopmental basis of mental illness," Frontiers in Neuroscience, vol. 17, no. 7, article 180, 2013.

[84] U. Meyer, M. Nyffeler, A. Engler et al., "The time of prenatal immune challenge determines the specificity of inflammationmediated brain and behavioral pathology," The Journal of Neuroscience, vol. 26, no. 18, pp. 4752-4762, 2006.

[85] J. H. Gilmore, L. F. Jarskog, S. Vadlamudi, and J. M. Lauder, "Prenatal infection and risk for schizophrenia: IL-1 $\beta$, IL-6, and TNF $\alpha$ inhibit cortical neuron dendrite development," Neuropsychopharmacology, vol. 29, no. 7, pp. 1221-1229, 2004.

[86] M. G. Chez, T. Dowling, P. B. Patel, P. Khanna, and M. Kominsky, "Elevation of tumor necrosis factor-alpha in cerebrospinal fluid of autistic childre," Pediatric Neurology, vol. 36, no. 6, pp. 361-365, 2007.

[87] S. Potvin, E. Stip, A. A. Sepehry, A. Gendron, R. Bah, and E. Kouassi, "Inflammatory cytokine alterations in schizophrenia: a systematic quantitative review," Biological Psychiatry, vol. 63, no. 8, pp. 801-808, 2008.

[88] P. Ashwood, P. Krakowiak, I. Hertz-Picciotto, R. Hansen, I. Pessah, and J. Van de Water, "Elevated plasma cytokines in autism spectrum disorders provide evidence of immune dysfunction and are associated with impaired behavioral outcome," Brain, Behavior, and Immunity, vol. 25, no. 1, pp. 40-45, 2011.

[89] S. D. Bilbo and J. M. Schwarz, "Early-life programming of laterlife brain and behavior: a critical role for the immune system," Frontiers in Behavioral Neuroscience, vol. 3, article 14, 2009.

[90] L. Bennet and A. Gunn, "The fetal origins of adult mental illness," in Early Life Origins of Health and Disease (Advances in Experimental Medicine and Biology), M. Wintour-Coghlan and J. Owens, Eds., pp. 204-211, Springer, New York, NY, USA, 2006.

[91] J. T. Morgan, G. Chana, C. A. Pardo et al., "Microglial activation and increased microglial density observed in the dorsolateral prefrontal cortex in autism," Biological Psychiatry, vol. 68, no. 4, pp. 368-376, 2010.

[92] C. A. Fredericks, E. M. Drabant, M. D. Edge et al., "Healthy young women with serotonin transporter SS polymorphism show a pro-inflammatory bias under resting and stress conditions," Brain, Behavior, and Immunity, vol. 24, no. 3, pp. 350-357, 2010.

[93] F. Macchi, J. R. Homberg, F. Calabrese et al., "Altered inflammatory responsiveness in serotonin transporter mutant rats," Journal of Neuroinflammation, vol. 10, article 116, 2013.

[94] A. Monji, T. A. Kato, Y. Mizoguchi et al., "Neuroinflammation in schizophrenia especially focused on the role of microglia," Progress in Neuro-Psychopharmacology \& Biological Psychiatry, vol. 42, pp. 115-121, 2013.

[95] K. Liaury, T. Miyaoka, T. Tsumori et al., "Morphological features of microglial cells in the hippocampal dentate gyrus of Gunn rat: a possible schizophrenia animal model," Journal of Neuroinflammation, vol. 9, article 56, 2012.

[96] R. M. Post, "Kindling and sensitization as models for affective episode recurrence, cyclicity, and tolerance phenomena," Neuroscience and Biobehavioral Reviews, vol. 31, no. 6, pp. 858-873, 2007.

[97] M. Berk, F. Kapczinski, A. C. Andreazza et al., "Pathways underlying neuroprogression in bipolar disorder: focus on inflammation, oxidative stress and neurotrophic factors," Neuroscience and Biobehavioral Reviews, vol. 35, no. 3, pp. 804-817, 2011. 
[98] R. L. Iyengar, S. Gandhi, A. Aneja et al., "NSAIDs are associated with lower depression scores in patients with osteoarthritis," American Journal of Medicine, vol. 126, no. 11, pp. 1017.el11017.e18, 2013.

[99] J. L. Harris, H. W. Yeh, I. Y. Choi et al., "Altered neurochemical profile after traumatic brain injury: 1H-MRS biomarkers of pathological mechanisms," Journal of Cerebral Blood Flow \& Metabolism, vol. 32, no. 12, pp. 2122-2134, 2012.

[100] D. A. Rossignol and R. E. Frye, "A review of research trends in physiological abnormalities in autism spectrum disorders: immune dysregulation, inflammation, oxidative stress, mitochondrial dysfunction and environmental toxicant exposures," Molecular Psychiatry, vol. 17, no. 4, pp. 389-401, 2012.

[101] X. Ming, M. Brimacombe, J. Chaaban, B. Zimmerman-Bier, and G. C. Wagner, "Autism spectrum disorders: concurrent clinical disorders," Journal of Child Neurology, vol. 23, no. 1, pp. 6-13, 2008.

[102] R. E. Frye, R. Delatorre, H. Taylor et al., "Redox metabolism abnormalities in autistic children associated with mitochondrial disease," Translational Psychiatry, vol. 3, article e273, 2013.

[103] S. Rose, S. Melnyk, O. Pavliv et al., "Evidence of oxidative damage and inflammation associated with low glutathione redox status in the autism brain," Translational Psychiatry, vol. 10, no. 2, article e134, 2012.

[104] A. Kulak, P. Steullet, J. H. Cabungcal et al., "Redox dysregulation in the pathophysiology of schizophrenia and bipolar disorder: insights from animal models," Antioxidants \& Redox Signaling, vol. 18, no. 12, pp. 1428-1443, 2013.

[105] A. Jorgensen, J. Krogh, K. Miskowiak et al., "Systemic oxidatively generated DNA/RNA damage in clinical depression: associations to symptom severity and response to electroconvulsive therapy," Journal of Affective Disorders, vol. 149, no. 1-3, pp. 355362, 2013.

[106] T. Durand, C. De Felice, C. Signorini et al., "F(2)-Dihomoisoprostanes and brain white matter damage in stage 1 Rett syndrome," Biochimie, vol. 95, pp. 86-90, 2013.

[107] J. Flatow, P. Buckley, and B. J. Miller, "Meta-analysis of oxidative stress in schizophrenia," Biological Psychiatry, vol. 74, no. 6, pp. 400-409, 2013.

[108] M. Bulut, S. Selek, H. S. Gergerlioglu et al., "Malondialdehyde levels in adult attention-deficit hyperactivity disorder," Journal of Psychiatry and Neuroscience, vol. 32, no. 6, pp. 435-438, 2007.

[109] Y. Dwivedi, H. S. Rizavi, R. R. Conley, R. C. Roberts, C. A. Tamminga, and G. N. Pandey, "Altered gene expression of brainderived neurotrophic factor and receptor tyrosine kinase B in postmortem brain of suicide subjects," Archives of General Psychiatry, vol. 60, no. 8, pp. 804-815, 2003.

[110] P. Sklar, S. B. Gabriel, M. G. McInnis et al., "Family-based association study of 76 candidate genes in bipolar disorder: BDNF is a potential risk locus," Molecular Psychiatry, vol. 7, no. 6, pp. 579-593, 2002.

[111] S. Sen, R. M. Nesse, S. F. Stoltenberg et al., "A BDNF coding variant is associated with the NEO personality inventory domain neuroticism, a risk factor for depression," Neuropsychopharmacology, vol. 28, no. 2, pp. 397-401, 2003.

[112] J. Kaufman, B.-Z. Yang, H. Douglas-Palumberi et al., "Brainderived neurotrophic factor-5-HTTLPR gene interactions and environmental modifiers of depression in children," Biological Psychiatry, vol. 59, no. 8, pp. 673-680, 2006.

[113] Z.-Y. Chen, D. Jing, K. G. Bath et al., "Genetic variant BDNF (Val66Met) polymorphism alters anxiety-related behavior," Science, vol. 314, no. 5796, pp. 140-143, 2006.
[114] S. Sen, R. Duman, and G. Sanacora, "Serum brain-derived neurotrophic factor, depression, and antidepressant medications: meta-analyses and implications," Biological Psychiatry, vol. 64, no. 6, pp. 527-532, 2008.

[115] A. Versace, A. C. Andreazza, L. T. Young et al., "Elevated serum measures of lipid peroxidation and abnormal prefrontal white matter in euthymic bipolar adults: toward peripheral biomarkers of bipolar disorder," Molecular Psychiatry, 2013.

[116] S. Najjar, D. M. Pearlman, S. Hirsch et al., "Brain biopsy findings link major depressive disorder to neuroinflammation, oxidative stress, and neurovascular dysfunction: a case report," Biological Psychiatry, 2013.

[117] E. A. Kosenko, G. Aliev, L. A. Tikhonova, Y. Li, A. C. Poghosyan, and Y. G. Kaminsky, "Antioxidant status and energy state of erythrocytes in Alzheimer dementia: probing for markers," CNS \& Neurological Disorders Drug Targets, vol. 11, no. 7, pp. 926-932, 2012.

[118] S. M. Cardoso, M. T. Proença, S. Santos, I. Santana, and C. R. Oliveira, "Cytochrome c oxidase is decreased in Alzheimer's disease platelets," Neurobiology of Aging, vol. 25, no. 1, pp. 105$110,2004$.

[119] F. Bosetti, F. Brizzi, S. Barogi et al., "Cytochrome c oxidase and mitochondrial F1F0-ATPase (ATP synthase) activities in platelets and brain from patients with Alzheimer's disease," Neurobiology of Aging, vol. 23, no. 3, pp. 371-376, 2002.

[120] M. Mancuso, M. Filosto, F. Bosetti et al., "Decreased platelet cytochrome c oxidase activity is accompanied by increased blood lactate concentration during exercise in patients with Alzheimer disease," Experimental Neurology, vol. 182, no. 2, pp. 421-426, 2003.

[121] K. Leuner, K. Schulz, T. Schütt et al., "Peripheral mitochondrial dysfunction in Alzheimer's disease: focus on lymphocytes," Molecular Neurobiology, vol. 46, no. 1, pp. 194-204, 2012.

[122] M. C. Puertas, J. M. Martínez-Martos, M. P. Cobo, M. P. Carrera, M. D. Mayas, and M. J. Ramírez-Expósito, "Plasma oxidative stress parameters in men and women with early stage Alzheimer type dementia," Experimental Gerontology, vol. 47, no. 8, pp. 625-630, 2012.

[123] E. Okun, T. V. Arumugam, S.-C. Tang et al., "The organotellurium compound ammonium trichloro(dioxoethylene- $0,0^{\prime}$ ) tellurate enhances neuronal survival and improves functional outcome in an ischemic stroke model in mice," Journal of Neurochemistry, vol. 102, no. 4, pp. 1232-1241, 2007.

[124] S. Nagotani, T. Hayashi, K. Sato et al., "Reduction of cerebral infarction in stroke-prone spontaneously hypertensive rats by statins associated with amelioration of oxidative stress," Stroke, vol. 36, no. 3, pp. 670-672, 2005.

[125] W. C. Lee, H. Y. Wong, Y. Y. Chai et al., "Lipid peroxidation dysregulation in ischemic stroke: plasma 4-HNE as a potential biomarker?" Biochemical and Biophysical Research Communications, vol. 425, no. 4, pp. 842-847, 2012.

[126] M. L. Selley, "(E)-4-Hydroxy-2-nonenal may be involved in the pathogenesis of Parkinson's disease," Free Radical Biology \& Medicine, vol. 25, no. 2, pp. 169-174, 1998.

[127] T. V. Ilic, M. Jovanovic, A. Jovicic, and M. Tomovic, "Oxidative stress indicators are elevated in de novo Parkinson's disease patients," Functional Neurology, vol. 14, no. 3, pp. 141-147, 1999.

[128] M. Bulut, S. Selek, Y. Bez et al., "Lipid peroxidation markers in adult attention deficit hyperactivity disorder: new findings for oxidative stress," Psychiatry Research, vol. 209, no. 3, pp. 638642, 2013. 
[129] Ö. Akyol, H. Herken, E. Uz et al., "The indices of endogenous oxidative and antioxidative processes in plasma from schizophrenic patients: the possible role of oxidant/antioxidant imbalance," Progress in Neuro-Psychopharmacology \& Biological Psychiatry, vol. 26, no. 5, pp. 995-1005, 2002.

[130] M. Ceylan, S. Sener, A. C. Bayraktar, and M. Kavutcu, "Oxidative imbalance in child and adolescent patients with attention-deficit/hyperactivity disorder," Progress in NeuroPsychopharmacology \& Biological Psychiatry, vol. 34, no. 8, pp. 1491-1494, 2010.

[131] L. H. Sanders and J. Timothy Greenamyre, "Oxidative damage to macromolecules in human Parkinson disease and the rotenone model," Free Radical Biology \& Medicine, vol. 62, pp. 111-120, 2013.

[132] M. Gulec, H. Ozkol, Y. Selvi et al., "Oxidative stress in patients with primary insomnia," Progress in Neuro-Psychopharmacology \& Biological Psychiatry, vol. 37, no. 2, pp. 247-251, 2012.

[133] J. Kalra, A. H. Rajput, S. V. Mantha, A. K. Chaudhary, and K. Prasad, "Oxygen free radical producing activity of polymorphonuclear leukocytes in patients with Parkinson's disease," Molecular and Cellular Biochemistry, vol. 112, no. 2, pp. 181-186, 1992.

[134] D. O. Cristalli, N. Arnal, F. A. Marra, M. J. T. de Alaniz, and C. A. Marra, "Peripheral markers in neurodegenerative patients and their first-degree relatives," Journal of the Neurological Sciences, vol. 314, no. 1-2, pp. 48-56, 2012.

[135] L. Kouti, M. Noroozian, S. Akhondzadeh et al., "Nitric oxide and peroxynitrite serum levels in Parkinson's disease: correlation of oxidative stress and the severity of the disease," European Review for Medical and Pharmacological Sciences, vol. 17, no. 7, pp. 964-970, 2013.

[136] C. Haxaire, F. R. Turpin, B. Potier et al., "Reversal of agerelated oxidative stress prevents hippocampal synaptic plasticity deficits by protecting d-serine-dependent NMDA receptor activation," Aging Cell, vol. 11, no. 2, pp. 336-344, 2012.

[137] L. Qin, Y. Liu, J. S. Hong, and F. T. Crews, "NADPH oxidase and aging drive microglial activation, oxidative stress, and dopaminergic neurodegeneration following systemic LPS administration," Glia, vol. 61, no. 6, pp. 855-868, 2013.

[138] P. Milani, G. Ambrosi, O. Gammoh, F. Blandini, and C. Cereda, "SOD1 and DJ-1 converge at Nrf2 pathway: a clue for antioxidant therapeutic potential in neurodegeneration," Oxidative Medicine and Cellular Longevity, vol. 2013, Article ID 836760, 12 pages, 2013.

[139] M. Y. Cheng, I.-P. Lee, M. Jin et al., "An insult-inducible vector system activated by hypoxia and oxidative stress for neuronal gene therapy," Translational Stroke Research, vol. 2, no. 1, pp. 92100, 2011.

[140] Y. Li, J. D. Paonessa, and Y. Zhang, "Mechanism of chemical activation of Nrf2," PLoS One, vol. 7, no. 4, Article ID e35122, 2012.

[141] L. Gan, M. R. Vargas, D. A. Johnson, and J. A. Johnson, "Astrocyte-specific overexpression of Nrf2 delays motor pathology and synuclein aggregation throughout the CNS in the alpha-synuclein mutant (A53T) mouse model," The Journal of Neuroscience, vol. 32, no. 49, pp. 17775-17787, 2012.

[142] T. G. Son, E. M. Kawamoto, Q. S. Yu, N. H. Greig, M. P. Mattson, and S. Camandola, "Naphthazarin protects against glutamateinduced neuronal death via activation of the Nrf2/ARE pathway," Biochemical and Biophysical Research Communications, vol. 433, no. 4, pp. 602-606, 2013.
[143] A. T. Dinkova-Kostova, W. D. Holtzclaw, R. N. Cole et al., "Direct evidence that sulfhydryl groups of Keapl are the sensors regulating induction of phase 2 enzymes that protect against carcinogens and oxidants," Proceedings of the National Academy of Sciences of the United States of America, vol. 99, no. 18, pp. 11908-11913, 2002.

[144] F. Hong, M. L. Freeman, and D. C. Liebler, "Identification of sensor cysteines in human Keapl modified by the cancer chemopreventive agent sulforaphane," Chemical Research in Toxicology, vol. 18, no. 12, pp. 1917-1926, 2005.

[145] H. Jiang, X. Tian, Y. Guo, W. Duan, H. Bu, and C. Li, "Activation of nuclear factor erythroid 2-related factor 2 cytoprotective signaling by curcumin protect primary spinal cord astrocytes against oxidative toxicity," Biological and Pharmaceutical Bulletin, vol. 34, no. 8, pp. 1194-1197, 2011.

[146] N. A. Kaidery, R. Banerjee, L. Yang et al., "Targeting Nrf2mediated gene transcription by extremely potent synthetic triterpenoids attenuate dopaminergic neurotoxicity in the MPTP mouse model of Parkinson's disease," Antioxidants \& Redox Signaling, vol. 18, no. 2, pp. 139-157, 2013.

[147] F. L'Episcopo, C. Tirolo, N. Testa et al., "Aging-induced Nrf2ARE pathway disruption in the subventricular zone drives neurogenic impairment in Parkinsonian mice via PI3K-Wnt/ $\beta$ Catenin dysregulation," The Journal of Neuroscience, vol. 33, no. 4, pp. 1462-1485, 2013.

[148] I. Pérez-de-Puig, A. Martín, R. Gorina, X. de la Rosa, E. Martinez, and A. M. Planas, "Induction of hemeoxygenase-1 expression after inhibition of hemeoxygenase activity promotes inflammation and worsens ischemic brain damage in mice," Neuroscience, vol. 243, pp. 22-32, 2013.

[149] A. M. Buga, C. J. Scholz, S. Kumar et al., "Identification of new therapeutic targets by genome-wide analysis of gene expression in the ipsilateral cortex of aged rats after stroke," PLoS One, vol. 7, Article ID e50985, 2012.

[150] M. Bousquet, F. Calon, and F. Cicchetti, "Impact of omega-3 fatty acids in Parkinson's disease," Ageing Research Reviews, vol. 10, no. 4, pp. 453-463, 2011.

[151] K. Joshi, S. Lad, M. Kale et al., "Supplementation with flax oil and vitamin C improves the outcome of Attention Deficit Hyperactivity Disorder (ADHD)," Prostaglandins Leukotrienes and Essential Fatty Acids, vol. 74, no. 1, pp. 17-21, 2006.

[152] A. J. Richardson and P. Montgomery, "The Oxford-Durham Study: a randomized, controlled trial of dietary supplementation with fatty acids in children with developmental coordination disorder," Pediatrics, vol. 115, no. 5, pp. 1360-1366, 2005.

[153] C. D. Kamat, S. Gadal, M. Mhatre, K. S. Williamson, Q. N. Pye, and K. Hensley, "Antioxidants in central nervous system diseases: preclinical promise and translational challenges," Journal of Alzheimer's Disease, vol. 15, no. 3, pp. 473-493, 2008.

[154] G. Bjelakovic, D. Nikolova, L. L. Gluud, R. G. Simonetti, and C. Gluud, "Mortality in randomized trials of antioxidant supplements for primary and secondary prevention: systematic review and meta-analysis," The Journal of the American Medical Association, vol. 297, no. 8, pp. 842-857, 2007.

[155] M. Høyer-Hansen, S. P. S. Nordbrandt, and M. Jäättelä, "Autophagy as a basis for the health-promoting effects of vitamin D," Trends in Molecular Medicine, vol. 16, no. 7, pp. 295$302,2010$.

[156] P. Tuohimaa, T. Keisala, A. Minasyan, J. Cachat, and A. Kalueff, "Vitamin D, nervous system and aging," Psychoneuroendocrinology, vol. 34, no. 1, pp. S278-S286, 2009. 
[157] R. K. Kaundal and S. S. Sharma, "Peroxisome proliferatoractivated receptor $\gamma$ agonists as neuroprotective agents," Drug News \& Perspectives, vol. 23, no. 4, pp. 241-256, 2010.

[158] S. Polvani, M. Tarocchi, and A. Galli, "PPAR and oxidative stress: $\operatorname{Con}(\beta)$ catenating NRF2 and FOXO," PPAR Research, vol. 2012, Article ID 641087, 15 pages, 2012.

[159] T. Haraguchi, K. Iwasaki, K. Takasaki et al., "Telmisartan, a partial agonist of peroxisome proliferator-activated receptor $\gamma$, improves impairment of spatial memory and hippocampal apoptosis in rats treated with repeated cerebral ischemia," Brain Research, vol. 1353, no. 1, pp. 125-132, 2010.

[160] K. Washida, M. Ihara, K. Nishio et al., "Nonhypotensive dose of telmisartan attenuates cognitive impairment partially due to peroxisome proliferator-activated receptor- $\gamma$ activation in mice with chronic cerebral hypoperfusion," Stroke, vol. 41, no. 8, pp. 1798-1806, 2010.

[161] T. Kishi, Y. Hirooka, and K. Sunagawa, "Telmisartan protects against cognitive decline via up-regulation of brainderived neurotrophic factor/tropomyosin-related kinase B in hippocampus of hypertensive rats," Journal of Cardiology, vol. 60, no. 6, pp. 489-494, 2012.

[162] F. Xu, J. Li, W. Ni, Y. W. Shen, and X. P. Zhang, "Peroxisome proliferator-activated receptor- $\gamma$ agonist 15d-prostaglandin J2 mediates neuronal autophagy after cerebral ischemiareperfusion injury," PLoS One, vol. 8, no. 1, Article ID e55080, 2013.

[163] K. Tureyen, R. Kapadia, K. K. Bowen et al., "Peroxisome proliferator-activated receptor- $\gamma$ agonists induce neuroprotection following transient focal ischemia in normotensive, normoglycemic as well as hypertensive and type-2 diabetic rodents," Journal of Neurochemistry, vol. 101, no. 1, pp. 41-56, 2007.

[164] S.-W. Park, J.-H. Yi, G. Miranpuri et al., “Thiazolidinedione class of peroxisome proliferator-activated receptor $\gamma$ agonists prevents neuronal damage, motor dysfunction, myelin loss, neuropathic pain, and inflammation after spinal cord injury in adult rats," Journal of Pharmacology and Experimental Therapeutics, vol. 320, no. 3, pp. 1002-1012, 2007.

[165] M. P. Pereira, O. Hurtado, A. Cárdenas et al., “The nonthiazolidinedione PPAR $\gamma$ agonist L-796,449 is neuroprotective in experimental stroke," Journal of Neuropathology and Experimental Neurology, vol. 64, no. 9, pp. 797-805, 2005.

[166] J. Chungpaibulpatana, T. Sumpatanarax, N. Thadakul, C. Chantharatreerat, M. Konkaew, and M. Aroonlimsawas, "Hyperbaric oxygen therapy in Thai autistic children," Journal of the Medical Association of Thailand, vol. 91, no. 8, pp. 1232-1238, 2008.

[167] D. A. Rossignol and L. W. Rossignol, "Hyperbaric oxygen therapy may improve symptoms in autistic children," Medical Hypotheses, vol. 67, no. 2, pp. 216-228, 2006.

[168] C. Joseph, A. M. Buga, R. Vintilescu et al., "Prolonged gaseous hypothermia prevents the upregulation of phagocytosis-specific protein annexin 1 and causes low-amplitude EEG activity in the aged rat brain after cerebral ischemia," Journal of Cerebral Blood Flow \& Metabolism, vol. 32, no. 8, pp. 1632-1642, 2012.

[169] Q. Ji, K. Hui, L. Zhang, X. Sun, W. Li, and M. Duan, “The effect of hydrogen-rich saline on the brain of rats with transient ischemia," Journal of Surgical Research, vol. 168, no. 1, pp. e95e101, 2011.

[170] J. Li, Y. Dong, H. Chen et al., "Protective effects of hydrogen-rich saline in a rat model of permanent focal cerebral ischemia via reducing oxidative stress and inflammatory cytokines," Brain Research, vol. 1486, no. 1, pp. 103-111, 2012.
[171] R. Khairova, R. Pawar, G. Salvadore et al., "Effects of lithium on oxidative stress parameters in healthy subjects," Molecular Medicine Reports, vol. 5, no. 3, pp. 680-682, 2012.

[172] D. M. Chuang, Z. Wang, and C. T. Chiu, "GSK-3 as a target for lithium-induced neuroprotection against excitotoxicity in neuronal cultures and animal models of ischemic stroke," Frontiers in Molecular Neuroscience, vol. 4, article 15, 2011.

[173] M. Pignitter, A. C. F. Gorren, S. Nedeianu, K. Schmidt, and B. Mayer, "Inefficient spin trapping of superoxide in the presence of nitric-oxide: implications for studies on nitric-oxide synthase uncoupling," Free Radical Biology \& Medicine, vol. 41, no. 3, pp. 455-463, 2006.

[174] M. Talarowska, P. Gałecki, M. Maes et al., "Nitric oxide plasma concentration associated with cognitive impairment in patients with recurrent depressive disorder," Neuroscience Letters, vol. 510, no. 2, pp. 127-131, 2012.

[175] T. Yoshitomi, A. Hirayama, and Y. Nagasaki, “The ROS scavenging and renal protective effects of $\mathrm{pH}$-responsive nitroxide radical-containing nanoparticles," Biomaterials, vol. 32, no. 31, pp. 8021-8028, 2011.

[176] T. M. Michel, A. J. Sheldrick, S. Camara, E. Grnblatt, F. Schneider, and P. Riederer, "Alteration of the pro-oxidant xanthine oxidase $(\mathrm{XO})$ in the thalamus and occipital cortex of patients with schizophrenia," World Journal of Biological Psychiatry, vol. 12 , no. 8, pp. 588-597, 2011.

[177] X. Hu, H. Zhou, D. Zhang et al., "Clozapine protects dopaminergic neurons from inflammation-induced damage by inhibiting microglial overactivation," Journal of NeuroImmune Pharmacology, vol. 7, no. 1, pp. 187-201, 2012.

[178] C. D. Pandya, K. R. Howell, and A. Pillai, "Antioxidants as potential therapeutics for neuropsychiatric disorders," Progress in Neuropsychopharmacology \& Biological Psychiatry, vol. 46, pp. 214-223, 2013.

[179] S. Dodd, M. Maes, G. Anderson, O. M. Dean, S. Moylan, and M. Berk, "Putative neuroprotective agents in neuropsychiatric disorders," Progress in Neuro-Psychopharmacology \& Biological Psychiatry, vol. 42, pp. 135-145, 2013.

[180] R. W. Grillo, G. L. Ottoni, R. Leke, D. O. Souza, L. V. Portela, and D. R. Lara, "Reduced serum BDNF levels in schizophrenic patients on clozapine or typical antipsychotics," Journal of Psychiatric Research, vol. 41, no. 1-2, pp. 31-35, 2007.

[181] M. Pedrini, I. Chendo, I. Grande et al., "Serum brain-derived neurotrophic factor and clozapine daily dose in patients with schizophrenia: a positive correlation," Neuroscience Letters, vol. 491, no. 3, pp. 207-210, 2011.

[182] C.-M. Lim, S.-W. Kim, J.-Y. Park, C. Kim, S. H. Yoon, and J.-K. Lee, "Fluoxetine affords robust neuroprotection in the postischemic brain via its anti-inflammatory effect," Journal of Neuroscience Research, vol. 87, no. 4, pp. 1037-1045, 2009.

[183] N. G. Wehner, M. Skov, G. Shopp, M. S. Rocca, and J. Clarke, "Effects of natalizumab, an $\alpha 4$ integrin inhibitor, on fertility in male and female guinea pigs," Birth Defects Research B, vol. 86, no. 2, pp. 108-116, 2009. 


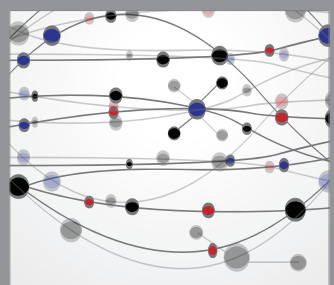

The Scientific World Journal
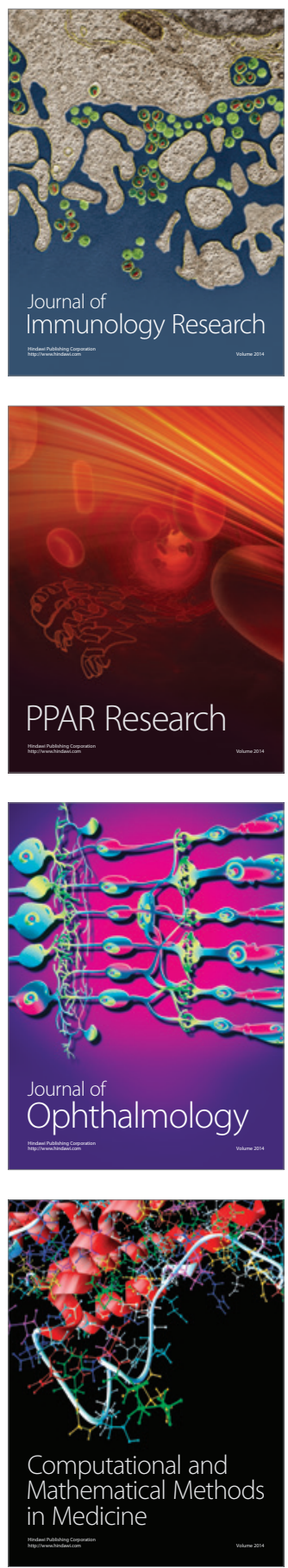

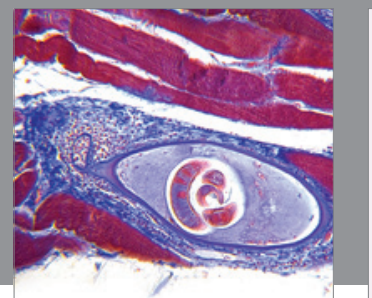

Gastroenterology

Research and Practice
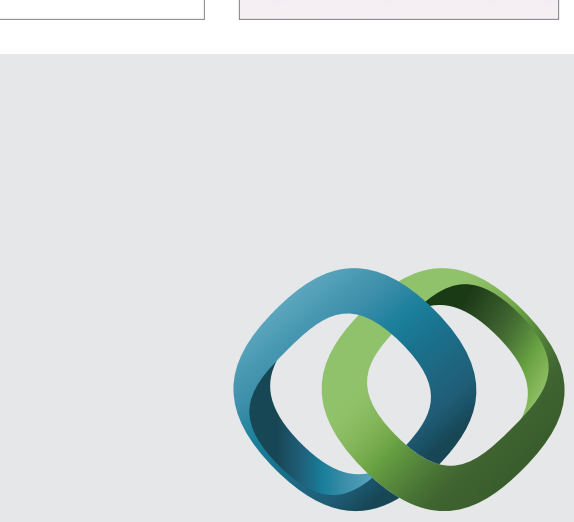

\section{Hindawi}

Submit your manuscripts at

http://www.hindawi.com
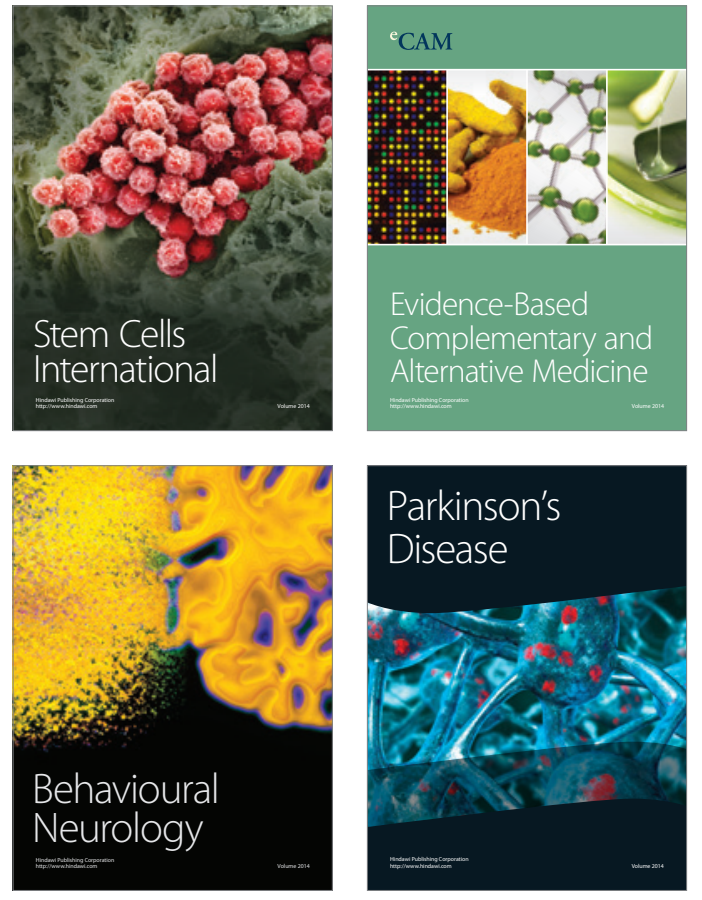
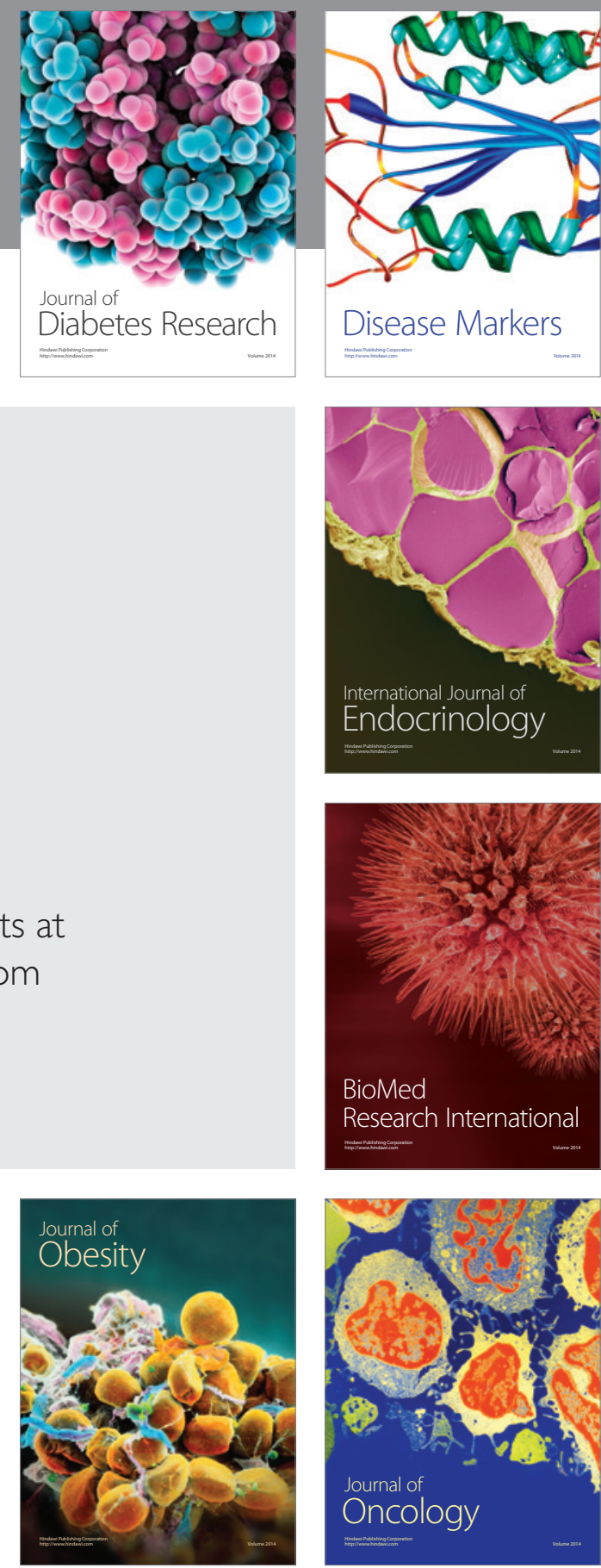

Disease Markers
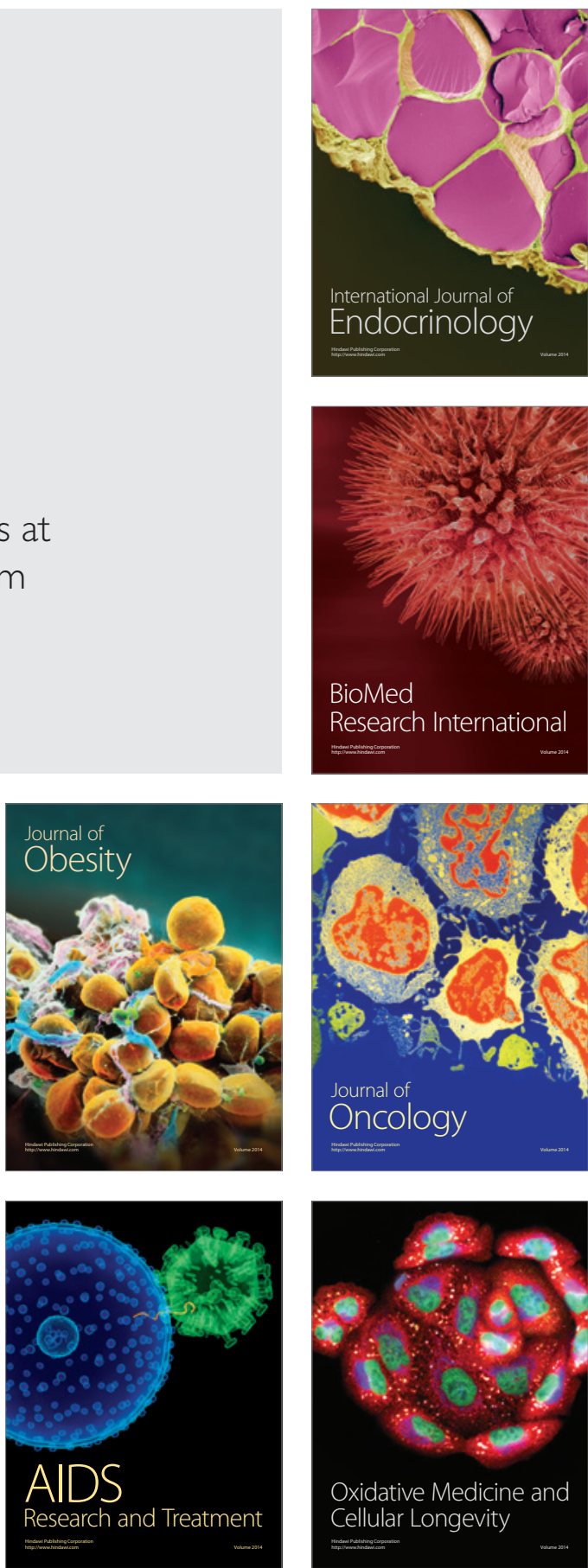